\title{
Circuit
}

Musiques contemporaines

\section{Foi et création : la fragilité du chant est sa force même}

\section{Gilles Tremblay}

Volume 5, numéro 1, 1994

Gilles Tremblay : réflexions

URI : https://id.erudit.org/iderudit/902085ar

DOI : https://doi.org/10.7202/902085ar

Aller au sommaire du numéro

Éditeur(s)

Les Presses de l'Université de Montréal

ISSN

1183-1693 (imprimé)

1488-9692 (numérique)

Découvrir la revue

Citer cet article

Tremblay, G. (1994). Foi et création : la fragilité du chant est sa force même. Circuit, 5(1), 22-25. https://doi.org/10.7202/902085ar d'utilisation que vous pouvez consulter en ligne.

https://apropos.erudit.org/fr/usagers/politique-dutilisation/ 


\section{La fragilité du chant est sa force même}

I Paru dans Le Devoir, 17 novembre 1984.

"Avez-vous vécu 1984 \&" Le seul fait d'écrire les mots que vous êtes en train de lire répond déjà à la question posée, on ne pourrait répondre non sans avoir été mort. Toutefois la question, à cause de sa brièveté même, engendre ses quoi, comment, pourquoi, devenant immense et dangereuse, débordant la référence d'Orwell. Y aurait-il des zones de non-vécu dans ce vécu ? Laissant au philosophe de l'existence cet aspect qui lui est familier, je limiterai plus modestement cette réflexion à partir de ma propre perception de 1984, en trois temps: situation du monde, signes d'espoir, nécessité.

La situation du monde porte souvent les noms de massacre, guerre, course aux armements, chômage, famine, assassinat, triomphe de la force brutale, mépris du faible, pollution de la nature, nivellement des forces vives par une croissance inquiétante des bureaucraties, absence de fonds consacrés à la recherche et à la création lle cri d'alarme lancé dans ces pages récemment par l'astrophysicien Hubert Reeves sur les conséquences que cela peut avoir 


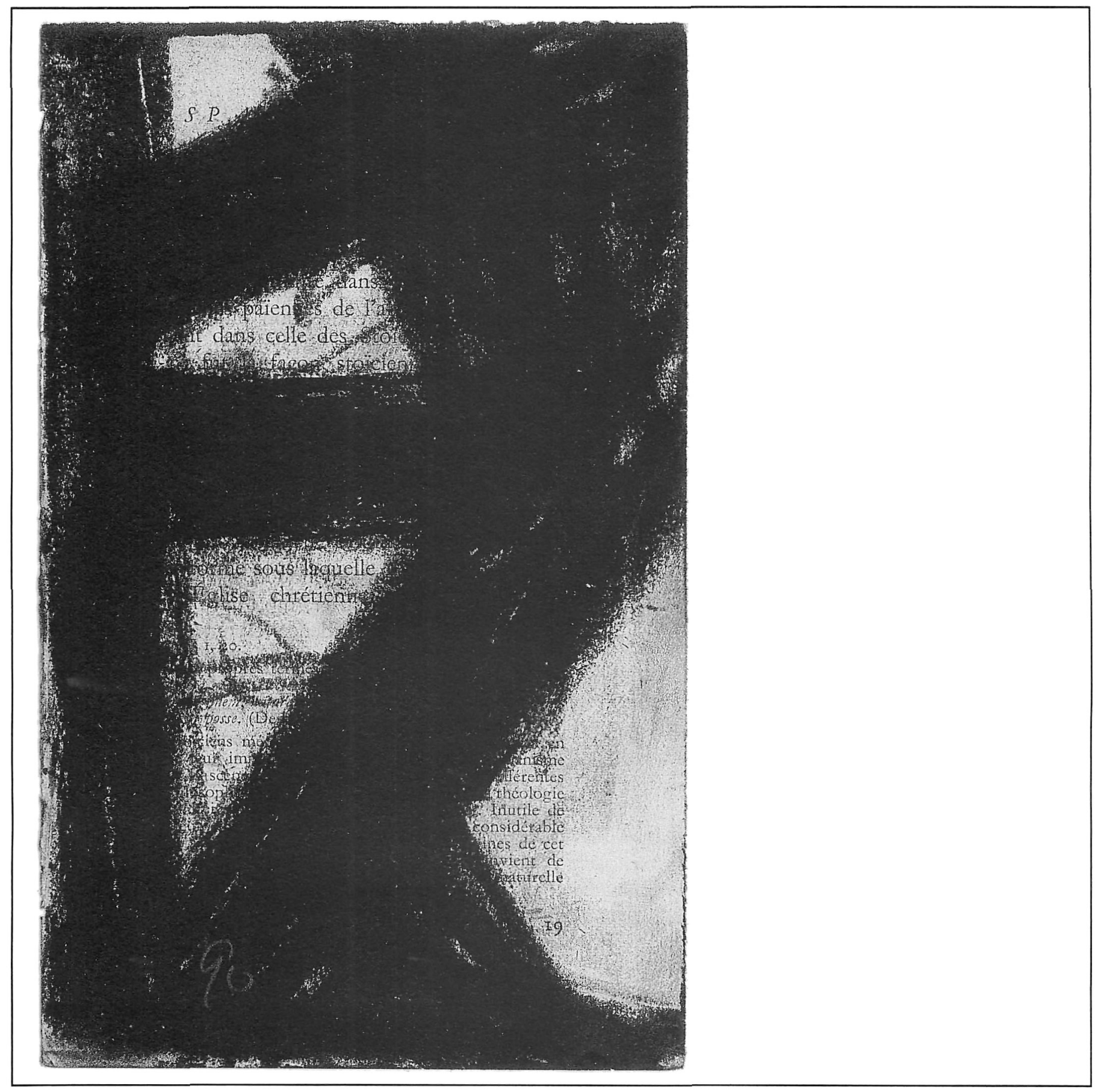


sur l'avenir de ce pays est significatif à cet égard). Cette série noire pourrait s'allonger. C'est essentiellement elle que reflète l'information, jusqu'à la banalisation, elle-même symptomatique d'un drame porteur d'insensibilité, évacuateur de l'humain.

Toutefois, à travers cette désolation, les signes d'espoir ne manquent pas. Je pense en particulier aux moments extraordinaires de la visite de Jean-Paul II, de conscience, et de tendresse donnée et reçue, éclosions de corolles en forme de mains d'enfants, beauté ineffable dans la façon de clamer le mot vivant.

Dans le domaine musical, la récente visite de Miguel Estrella, merveilleux pianiste argentin libéré de prison grâce aux pressions internationales, ef fondateur du mouvement appelé «musique-espérance» prend un sens prophétique par l'association même de ces deux mots à ce moment-ci : il y a tant de démissions, de l'à-quoi-bon jusqu'aux nouvelles esthétiques d'un néoconservatisme aux nostalgies fort peu dynamiques. Mais l'événement musical majeur qui a la valeur symbolique la plus chargée de sens à l'époque où nous vivons est sans aucun doute la création du Saint-François d'Assise d'Olivier Messiaen à l'Opéra de Paris. C'est, bien sûr, une œuvre aux dimensions généreuses tant pour la durée que pour le nombre des effectifs, échos des Mystères du Moyen Âge et des Passions de Jean-Sébastien Bach: qu'une telle œuvre soit née à ce moment-ci de l'histoire n'est pas fortuit. Voilà bien l'audace qui, à sa manière, est la plus parente de celle de François, par son aspect de fraîcheur et d'inusité. La beauté poétique, accordée au temps présent, dépasse souvent l'auteur, ce qui est encore plus merveilleux. Les dernières paroles, chantées par le chœur, ne sauraient être plus actuelles: « De la douleur, de la faiblesse, et de l'ignominie: il ressuscite de la force, de la gloire, de la joie! ».

A cause même du drame de notre époque, mais aussi des étincelles qui en ponctuent la nuit, porteuses de la promesse de la chaleur, une sorte d'urgence s'impose, aussi impérieuse qu'irrationnelle : la nécessité essentielle d'écrire, de participer ainsi au rythme, celui qui est cohésion de l'univers, comme le tenant ensemble, de la molécule aux étoiles, en passant par le cycle des saisons et le battement du cœur, comme si ce rythme était le porteur palpitant du jaillissement premier jusqu'aux berges du présent. Geste du Créateur.

Au cœur du drame, la fragilité du chant est sa force même, aux confins du silence. 
Dans la nuit, de Calcutta à Montréal, des mains assistent le mourant, reçoivent le naissant, porteuses de vie.

Milliers de gestes discrets: autant d'étincelles. 